\title{
Microstructure and Mechanical Properties of TiN/TiCN/TiC Multilayer Thin Films Deposited by Magnetron Sputtering Abbas Razmi *, Ruhi Yeşildal
}

\author{
Ataturk University, Faculty of Engineering, Erzurum, Turkey \\ ryesil@atauni.edu.tr (R.Y.) \\ *Correspondence: abbas.razmi11@ogr.atauni.edu.tr; abbasrazmi@hotmail.com Tel: +90-554-935-3969
}

\begin{abstract}
Enhancement of mechanical properties by using TiN/TiCN/TiC multilayer thin films deposited on commercially pure cast Titanium (CP-Ti), Ti6A14V and silicon ( $\mathrm{Si}$ ) substrates via magnetron sputtering technique was investigated in this study. The structural, chemical and mechanical properties of the coatings were characterized by X-ray diffraction (XRD), X-ray photoelectron spectroscopy (XPS), scanning electron microscopy (SEM), nanoindentation and scratch test. Results of the XRD analysis showed reflections corresponded to FCC (1 111 ) cubic and polycrystalline structure for TiN/TiCN/TiC films. XPS analysis revealed formation of titanium nitride, titanium carbonitride and titanium carbide in the coatings. According to SEM images, the coatings demonstrated dense cross-sectional morphology and columnar structure as well as good adhesion to the substrate with a thickness of $1.77 \mu \mathrm{m}$ deposited on silicon $\left(\begin{array}{lll}1 & 0 & 0\end{array}\right)$. Scratch and nanoindentation test results showed the best mechanical behavior for the coated Ti6Al4V substrate material with the $19.96 \mathrm{GPa}$ hardness and $25 \mathrm{~N}$ critical load values, because of its higher hardness and toughness of substrate in compared to $\mathrm{Cp}$-Ti substrate.
\end{abstract}

Keywords: Magnetron sputtering; TiN/TiCN/TiC film; Cp-Ti; Ti6A14V; Adhesion; Scratch; Nanoindentation 


\section{Introduction}

Titanium and its alloys because of their low density and elastic modulus, high corrosion resistance, biocompatibility and long fatigue life are widely used in spacecraft, automotive, dentistry, orthopedic field and medical industry [1,2]. Various deposition techniques such as chemical vapor deposition (CVD) [3], plasma enhanced chemical vapor deposition (PECVD) [4], magnetron sputtering [5], and thermal spraying [6, 7] have been used to deposition of TiCN coatings.

Hard coatings such as TiN, $\mathrm{CrN}, \mathrm{ZrN}, \mathrm{WC}, \mathrm{WC}-\mathrm{Co}, \mathrm{WC}-\mathrm{Ni}, \mathrm{ZrCN}$ and TiCN coatings as a first generation of single layer played an important role due to their higher hardness and toughness and also lower friction coefficient compared to high-speed steel and cemented carbide [8]. TiCN and $\mathrm{ZrCN}$ coatings are known as protective coating materials which have specifically been used because of their high melting point, extreme hardness, and high thermal conductivity $[9,10]$.

TiN films are commercially important due to their high hardness, high thermal, chemical stability and wear resistance [11-13]. As a hard ceramic material, TiN films usually are deposited on Titanium, steel and aluminum substrate materials. The TiN coatings are useful in some applications such as cutting tools and load bearing parts [14]. TiCN films also exhibits excellent wear resistance, high hardness and good corrosion resistance. These properties along with noncytotoxic character make TiCN films ideal for biomedical applications [15].TiN/TiCN multilayer coatings are expected to show higher hardness and wear resistance in compared with TiN and TiCN thin films. Su and Kao [16] showed that TiN/TiCN multilayer thin films have excellent mechanical properties, superior chemical stability, good wear and corrosion resistance. The aim of this work is to investigate microstructure and mechanical properties of TiN/TiCN/TiC multilayer thin films deposited on silicon CP-Ti and Ti6Al4V substrates by magnetron sputtering technique.

\section{Experimental Details}

CP-Ti (grade 4) and Ti6A14V (grade 5) with $0.02 \mu \mathrm{m}$ surface roughness were used as substrate materials. These samples were cut in $25 \times 25 \times 3$ dimensions by using abrasive water jet method. Chemical composition of samples is given in Table 1 . Samples were ultrasonically cleaned with acetone and ethanol, respectively. TiN/TiCN/TiC multilayered films were deposited on silicon (1 0 0), CP-Ti and Ti6Al4V substrates by using a DC closed field unbalanced magnetron sputtering system produced by Teer Coatings Ltd (plasmag-550). The placement of magnetrons and targets in coating device is given in Figure 1.

Two Titanium targets with $10 \mathrm{~cm}$ of diameter and a purity at $99.9 \%$ for both targets have been used for synthesize of the films. The sputtering gas was a mixture of $\mathrm{Ar}$ and $\mathrm{N}_{2}$. The $\mathrm{C}_{2} \mathrm{H}_{2}$ was used to prepare the carbon content of the coatings. The deposition was carried out at a bias voltage 
of $-60 \mathrm{~V}$, a target current of $6 \mathrm{~A}$ and a distance from substrate to target of $90 \mathrm{~mm}$. Following putting samples into chamber, the chamber was pumped down to a base pressure of $2.5 \times 10^{-3}$ tor. Afterwards, substrate materials were cleaned by ion bombardments for 20 min to remove oxide layers and surface contaminations. Before deposition of the TiN/TiCN/TiC multilayer film, Ti interlayer film was grown for $5 \mathrm{~min}$, which could be beneficial to good adhesion properties [17]. Experimental parameters of TiN/TiCN/TiC coating are shown in table 2.

Table 1. Chemical composition of CP-Ti and Ti6Al4V substrate materials (wt. \%)

\begin{tabular}{lcccccc}
\hline Substrates & Ti & V & Fe & Al & Sn & Cu \\
\hline Ti6Al4V & 89.8 & 3.78 & 0.03 & 6.31 & 0.05 & 0.01 \\
\hline CP- Ti & 99.8 & 0.05 & 0.09 & 0.005 & 0.099 & 0.01
\end{tabular}

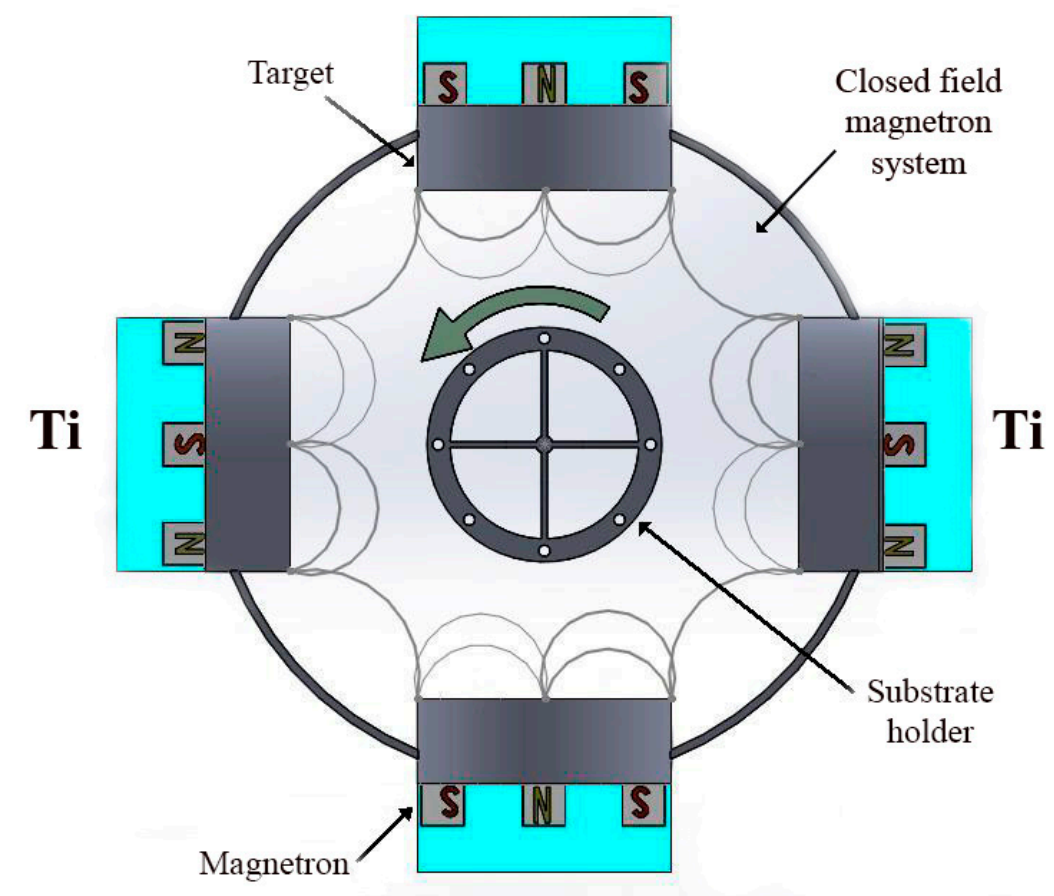

Figure 1. The placement of magnetrons inside the PLASMAG-550 device 
Table 2. The TiN/TiCN/TiC multilayer thin film obtained by variation of $\mathrm{N}_{2}$ and $\mathrm{CH}_{4}$ flow rate.

\begin{tabular}{|c|c|c|c|c|c|}
\hline $\begin{array}{l}\text { Ar flow } \\
\text { rate (\%) }\end{array}$ & $\begin{array}{l}\mathrm{N}_{2} \text { flow } \\
\text { rate }(\%)\end{array}$ & $\begin{array}{c}\mathrm{C}_{2} \mathrm{H}_{2} \text { flow } \\
\text { rate (\%) }\end{array}$ & $\begin{array}{c}\text { Ti target } \\
\text { current }(\mathrm{A})\end{array}$ & $\begin{array}{c}\text { Work } \\
\text { time (min) }\end{array}$ & Phase \\
\hline 100 & 0 & 0 & 0 & 20 & Ion cleaning \\
\hline 100 & 0 & 0 & 6 & 5 & $\mathrm{Ti}$ \\
\hline 40 & 60 & 0 & 6 & 10 & $\mathrm{TiN}$ \\
\hline 25 & 5 & 70 & 6 & 10 & TiCN \\
\hline 25 & $5 \rightarrow 50$ & $70 \rightarrow 25$ & 6 & 35 & $\begin{array}{c}\text { TiCN } \\
\text { (gradual) }\end{array}$ \\
\hline 75 & 0 & 25 & 6 & 15 & $\mathrm{TiC}$ \\
\hline
\end{tabular}

Surfaces morphology and cross-section of the multilayer TiN/TiCN/TiC thin films deposited on CP-Ti, Ti6Al4V and silicon substrates were observed by Quanta 250 FEG model scanning electron microscope. Surface structure and fractured crystalline structure of the film was investigated by using the GNR X-Ray Explorer diffractometer with $\mathrm{CuK} \alpha$ radiation $(\lambda=1.5406 \AA)$ at an incident angle from 20 to 60 . The chemical composition of various compounds of the coating surface and subsurface was performed by XPS (PHI-5000 versaprobe) with monochromatized Al Ka X-ray source at pass energy of $58.75 \mathrm{eV}$. In order to obtain insight into the chemical states of the film, the XPS Ti2p, N1s and C1s core-level spectroscopy of the film were examined at pass energy of $187.85 \mathrm{eV}$ and samples were sputtered by argon to remove the probable contaminations and or oxidations from the film surfaces.

The adhesion force of the TiN/TiCN/TiC film was measured by means of scratch test. The test was conducted by CSM Revetest Scratch Tester in dry atmosphere condition with a progressive load sliding between 0-30 $\mathrm{N}$ over the coating surfaces using Rockwell-C indenter tip with radius of 0.2 $\mathrm{mm}$. The loading rate and track length were $100 \mathrm{~N} / \mathrm{min}$ and $3 \mathrm{~mm}$, respectively. Instron hardness tester was used to measure the nano-hardness values of TiN/TiCN/TiC films deposited on the surface of CP-Ti and Ti6Al4V substrates. The applied load was $10 \mathrm{mN}$, a loading time of $15 \mathrm{~s}$, waiting time of $10 \mathrm{~s}$, discharging time of $15 \mathrm{~s}$ and thermal sliding time of $45 \mathrm{~s}$.

\section{Results and Discussion}

\subsection{Microstructure and Composition Examination}

The XRD pattern of TiN/TiCN/TiC multilayers film deposited on silicon $\left(\begin{array}{lll}1 & 0 & 0\end{array}\right)$ is given in Figure 2. XRD pattern indicated that the coating was consisted of FCC $\left(\begin{array}{lll}1 & 1 & 1\end{array}\right)$ cubic and polycrystalline structure of TiN-TiCN-TiC phase corresponding to the (lll 111$),\left(\begin{array}{lll}1 & 0 & 0\end{array}\right),\left(\begin{array}{lll}1 & 0 & 1\end{array}\right)$ and $\left(\begin{array}{lll}2 & 0 & 0\end{array}\right)$ planes 
[18]. Tendency of XRD peak was observed for $\left(\begin{array}{lll}1 & 1 & 1\end{array}\right)$ plane which could be verified by the highest intensity belongs to TiN (llll) or TiCN $\left(\begin{array}{lll}1 & 1 & 1\end{array}\right)$ planes [19].

XPS was used to determine chemical composition of the film's surface and depth profiling. As a results, Figure 3(a). showed that Ti2p had two evidential peaks located at 455 and $460.8 \mathrm{eV}$, respectively associated to Ti $2 \mathrm{p} 3 / 2$ and Ti $2 \mathrm{p} 1 / 2$. At the same time, a dominant N1s peak can be seen at the $397.5 \mathrm{eV}$ position. XPS spectra of Ti2p, N1S and C1s of the film are shown in Figure 3(b). Ti2p at binding energy of 455 and $461 \mathrm{eV}$ was observed for TiCN confirmed by the $\mathrm{C} 1 \mathrm{~s}$ peak at $285 \mathrm{eV}$ and N1s peak at $397 \mathrm{eV}$. XPS result of TiC uppermost layer of the film are given in Figure 3(c). Ti2p XPS peaks were consisted of two doublets (Ti 2p3/2 and Ti 2p1/2) at the binding energy of $459.1 \mathrm{eV}$ and $465 \mathrm{eV}$, respectively. The $\mathrm{C} 1 \mathrm{~s}$ spectrum showed a peak at the position of $286.1 \mathrm{eV}$ [20]. As mentioned earlier, it was found that titanium nitride (TiN), titanium carbonitride (TiCN) and titanium carbide (TiC) are mainly formed in the coating.

SEM was used to examine the changes in the surfaces and fractured cross-section of the coatings. As seen in Figure 4. both coated substrates were demonstrated the structural properties of dense, compact and fine-grain so that there was no significant difference when compared from the way of structure viewpoint. Cross-section SEM images of TiN/TiCN/TiC deposited on silicon (Figure 5) showed that the coatings had dense and columnar structure and thickness of film reached about $1.77 \mu \mathrm{m}$.

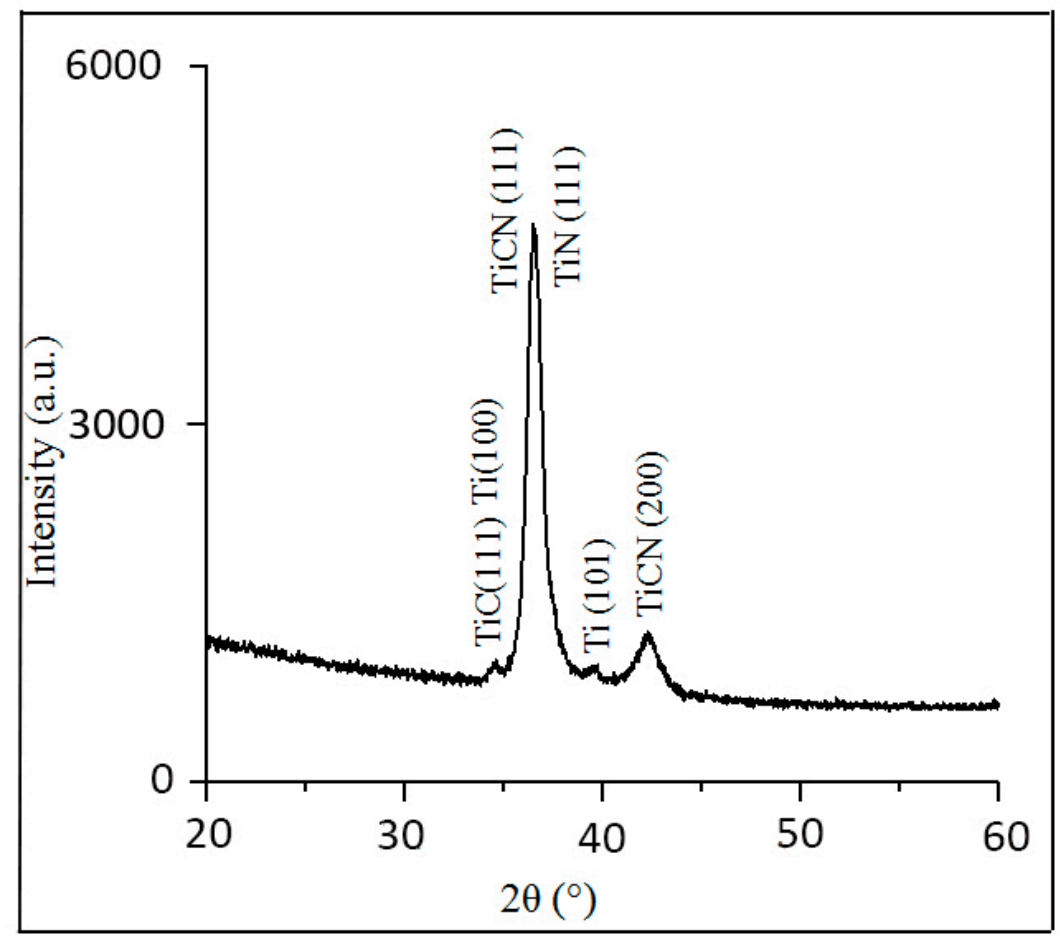

Figure 2. The XRD spectrums of the TiN/TiCN/TiC films deposited on the silicon surface 
(a)
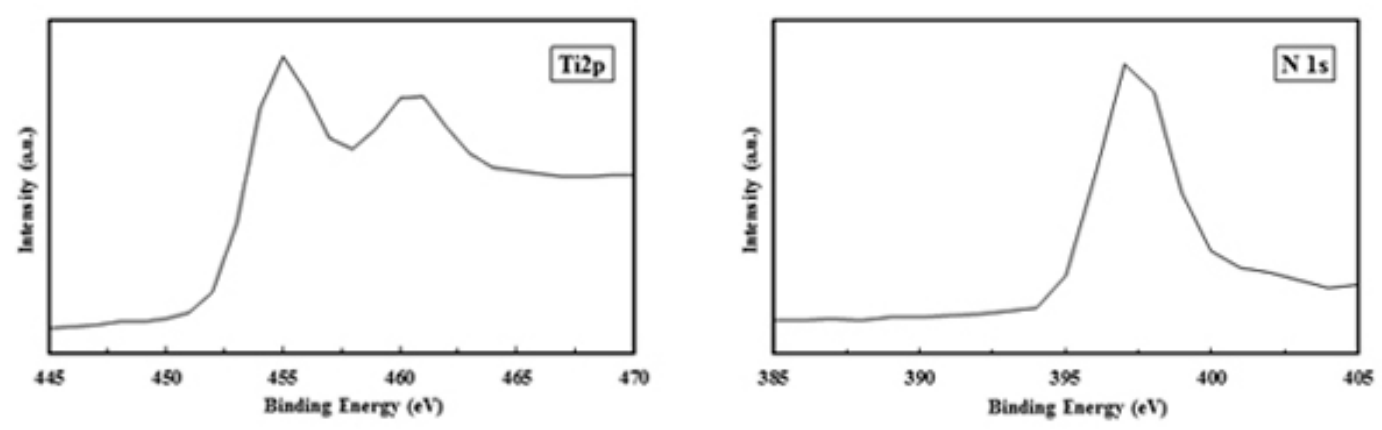

(b)
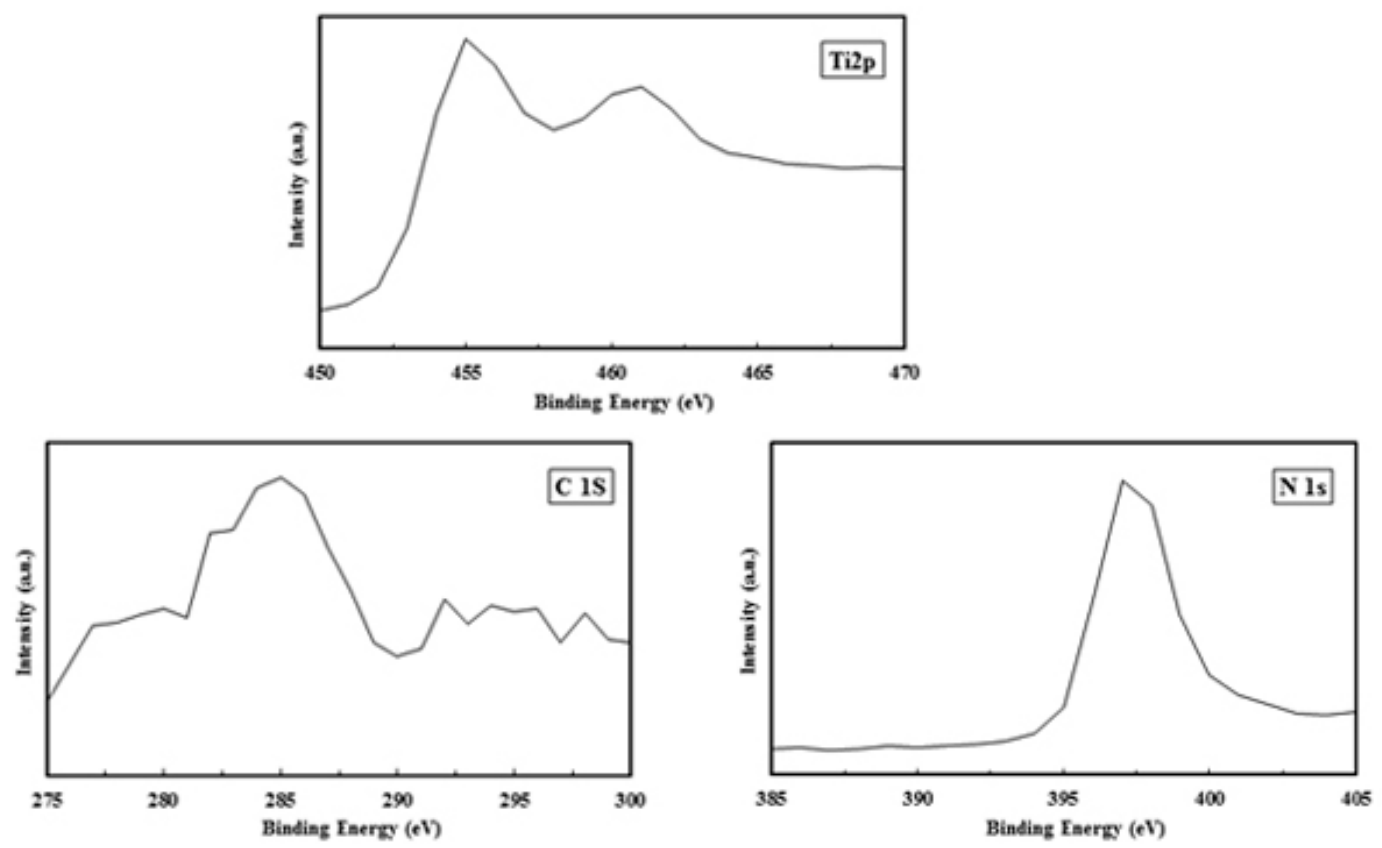

(c)
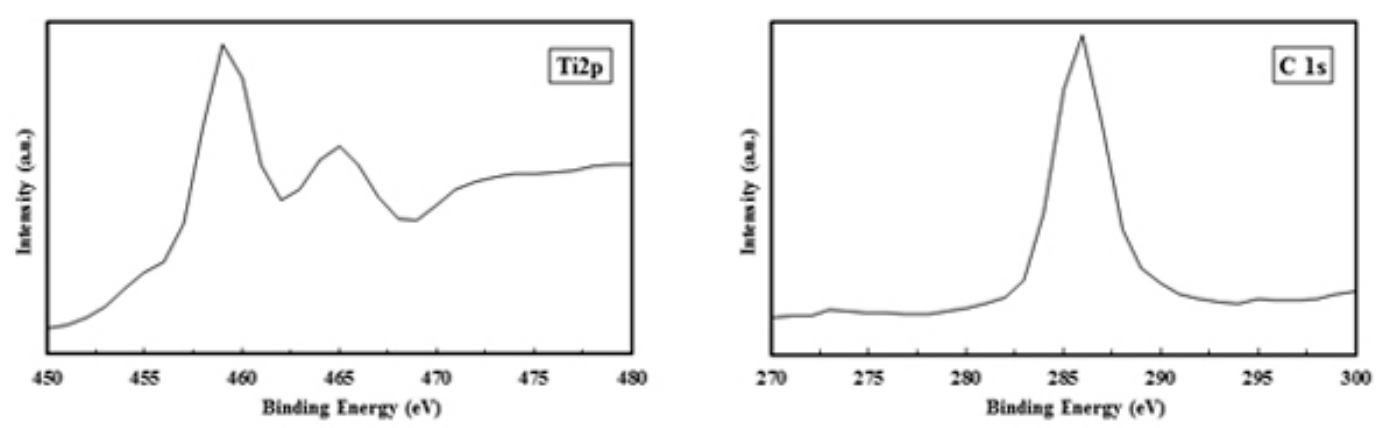

Figure 3. XPS spectra of TiN/TiCN/TiC multilayer film; (a) TiN, (b) $\mathrm{TiCN}$, and (c) $\mathrm{TiC}$ 


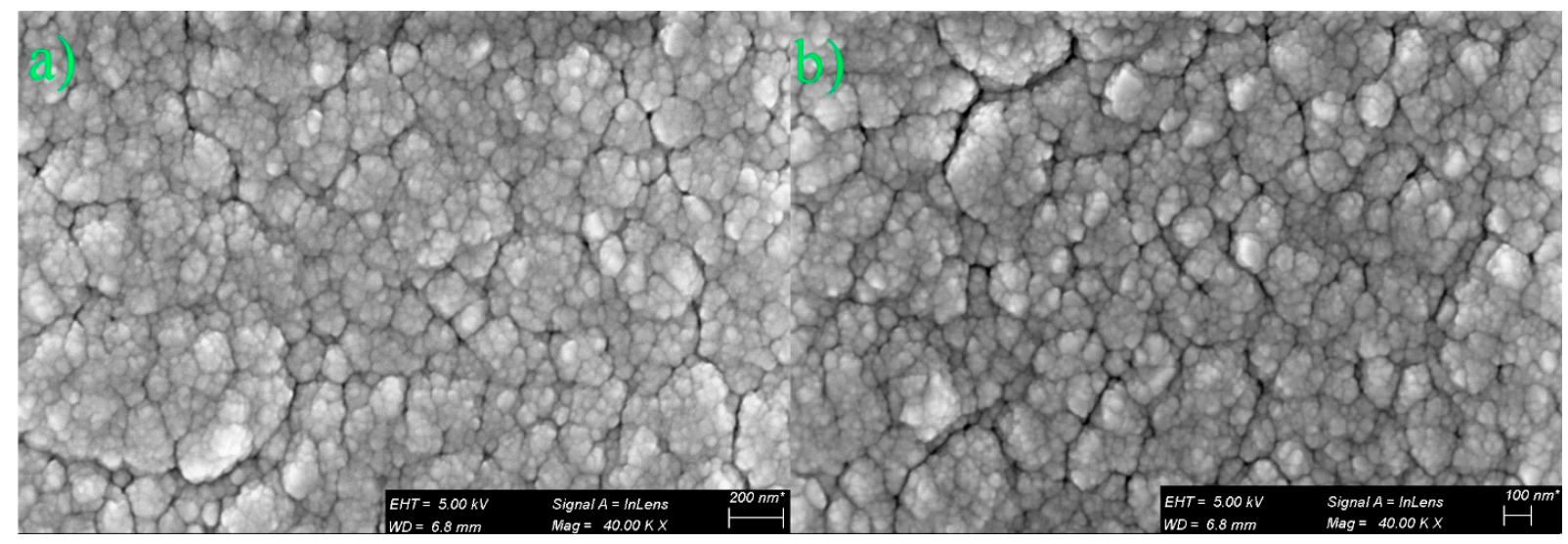

Figure 4. SEM images of TiN/TiCN/TiC coatings; (a) CP-Ti substrate, and (b) Ti6Al4V substrate

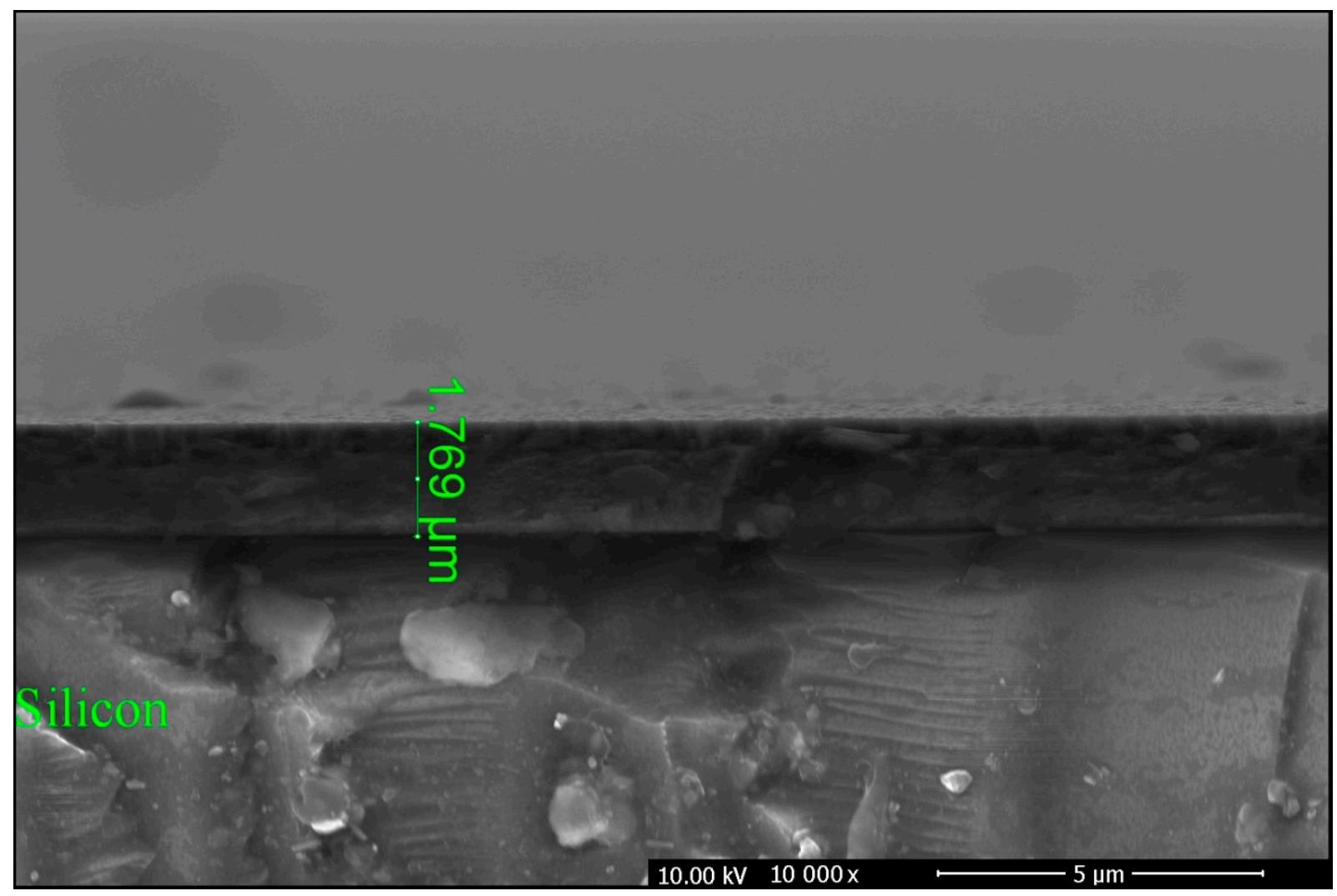

Figure 5. Cross-section SEM images of the silicon substrate 


\subsection{Mechanical Properties}

\subsubsection{Scratch Test:}

Adhesion test of TiN/TiCN/TiC film deposited on CP-Ti and Ti6Al4V substrates via magnetron sputtering were carried out by the scratch test. The value changes chart of coated CP-Ti and Ti6Al4V substrates of friction force, coefficient of friction and normal force obtained from the scratch test are given in Figure 6. At the coated CP-Ti substrate, when the load value reached to $6 \mathrm{~N}$, initial small cohesive fractures $\left(\mathrm{Lc}_{1}\right)$ began to show and followed up to $14 \mathrm{~N}$. These cohesive cracks widely formed on coating surface and present ductile fracture. First adhesive fractures occurred at $14 \mathrm{~N}\left(\mathrm{Lc}_{2}\right)$, where coating started to separate from the substrate in the form of brittle fracture. At the coated Ti6Al4V substrate, there was not any remarkable cracks on the film surface up to $10 \mathrm{~N}$. The significant cohesive cracks in the coating was occurred at $10 \mathrm{~N}$ load $\left(\mathrm{Lc}_{1}\right)$. When the load increased, the slightly adhesive cracks came into sight at $17 \mathrm{~N}\left(\mathrm{Lc}_{2}\right)$.

Previous studies have reported that the critical load values of TiCN coatings under different growth conditions were in the range from $6 \mathrm{~N}$ to $45 \mathrm{~N}$ [21]. SEM images of scratching test of CP-Ti and Ti6Al4V samples are given in Figure 7. When the SEM images were examined it was seen that due to the tensile stress on the coating surface, first cohesive cracks were started in the vertical direction of the scratch path and defined as $\mathrm{Lc}_{1}$ critical load [22]. With increasing the normal load value, the coating being separated from the substrate material and causes adhesive fractures [23]. The critical load values of TiN/TiCN/TiC coating deposited on CP-Ti substrate were $6 \mathrm{~N}$ and $14 \mathrm{~N}$, respectively (Figure 6a). The Ti6Al4V substrate with $10 \mathrm{~N}$ and $17 \mathrm{~N}$ critical loads indicated better scratch properties (higher hardness and strength values) in compared with CP-Ti substrate (Figure $6 \mathrm{~b}$ ). The reason for this result is that the critical load can be influenced by the properties of the substrate material because the coated hard and high-toughness substrates shows higher critical loads [24]. Critical load results were also confirmed by SEM images of scratch tracks (Figure 7). 


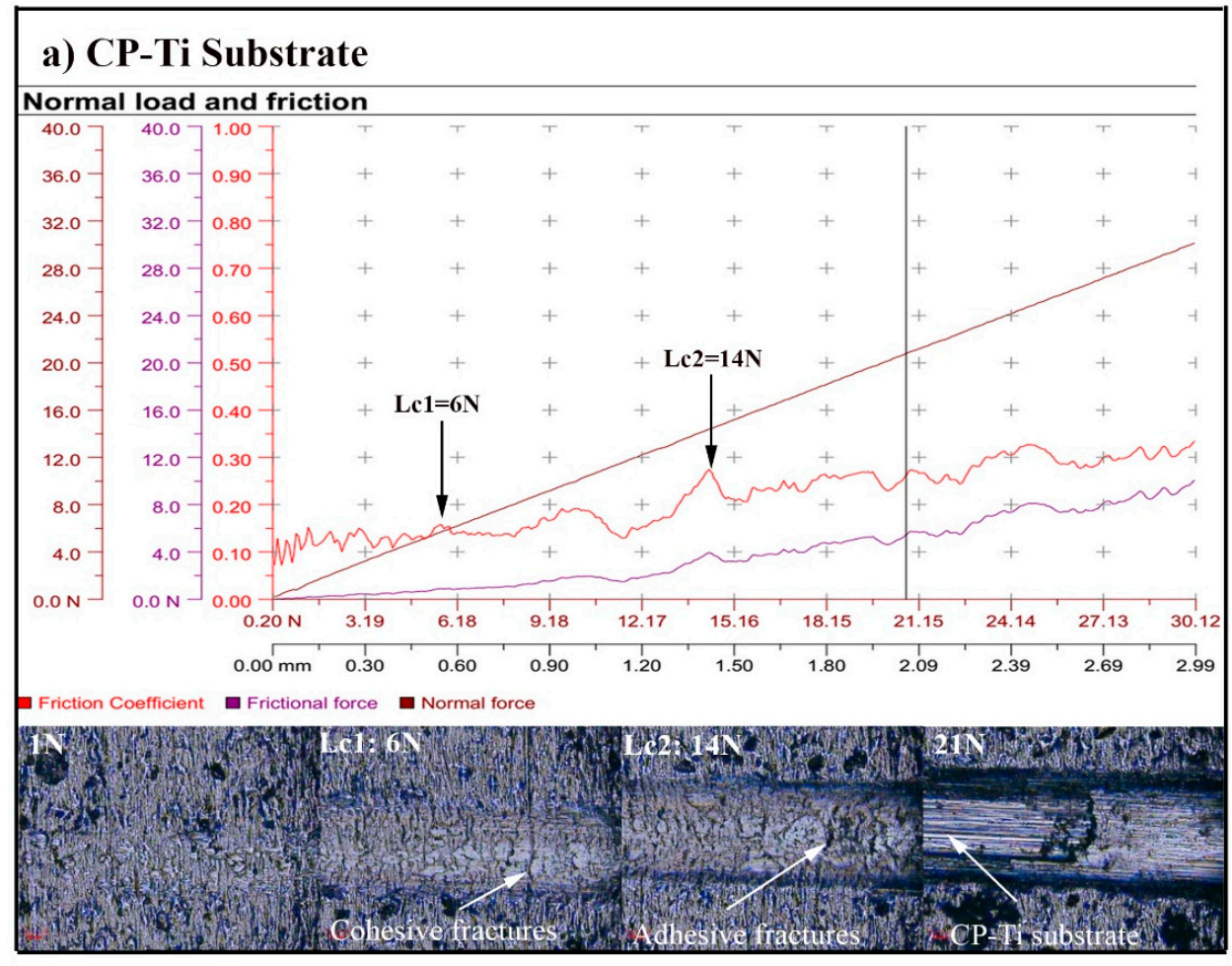

b) Ti6Al4V substrate

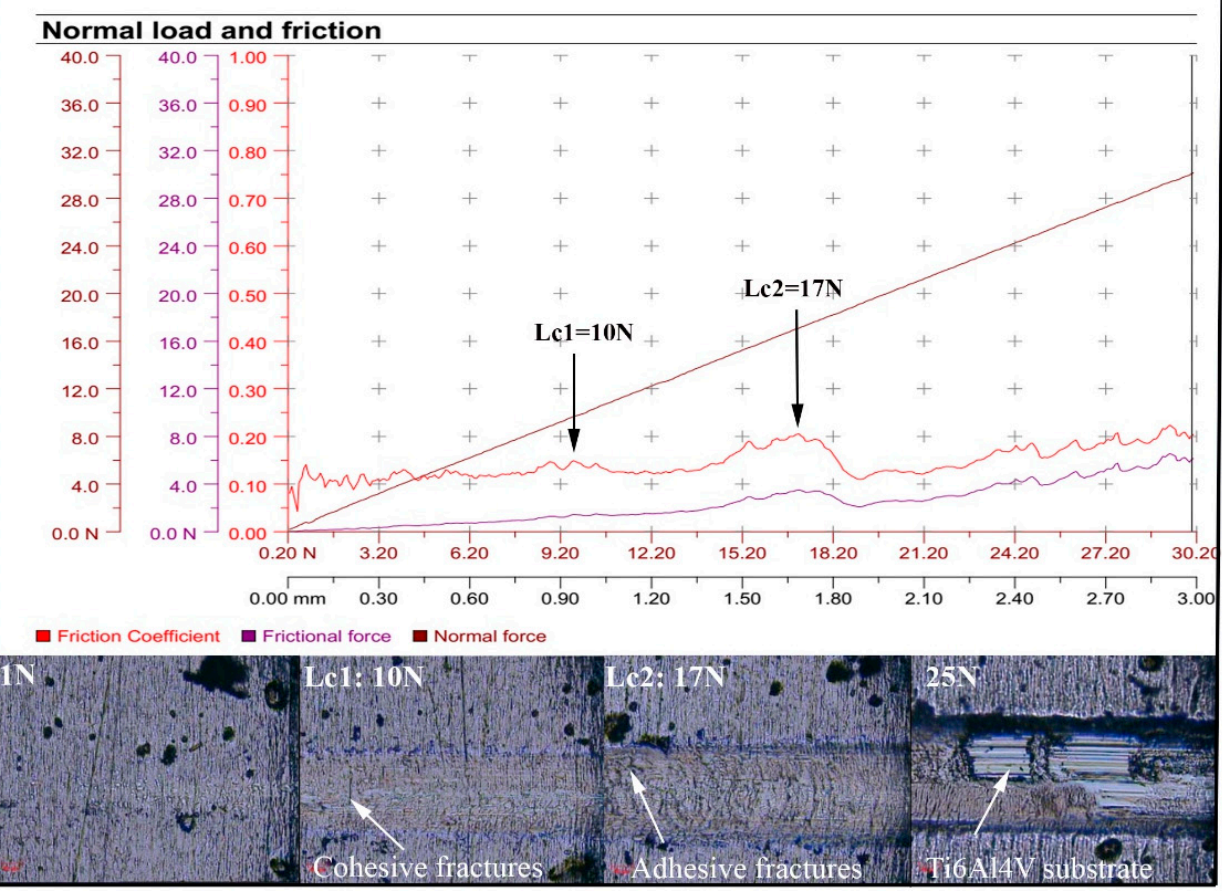

Figure 6. Friction force, coefficient of friction, normal force values graph and optic microscope images of (a) $\mathrm{CP}-\mathrm{Ti}$ and (b) Ti6Al4V substrates 


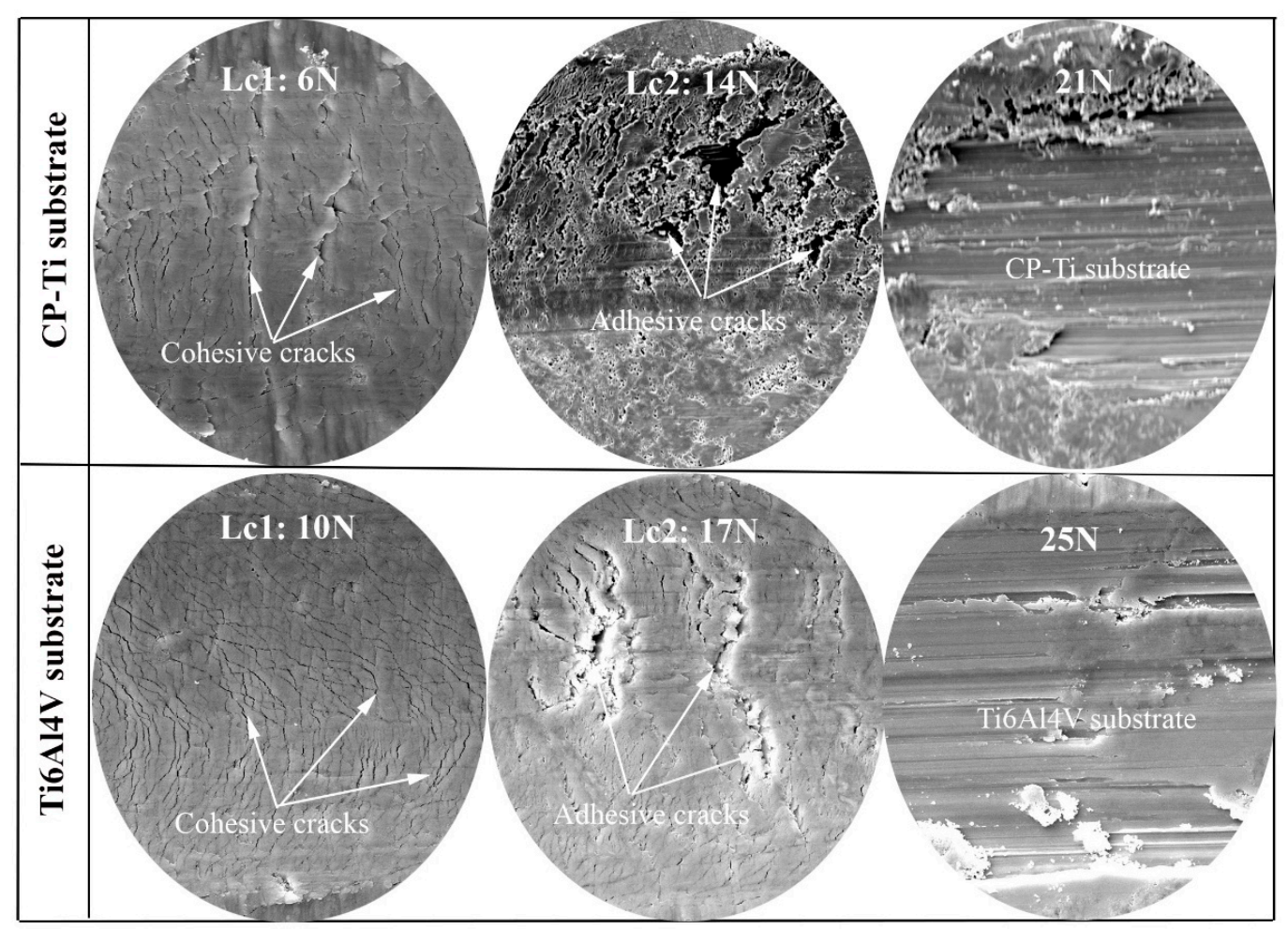

Figure 7. SEM images of scratch tracks of CP-Ti and Ti6Al4V substrates

\subsubsection{Nano-Hardness Measurements}

Figure 8. gives a typical loading-unloading indentation curves of TiN/TiCN/TiC film coated on $\mathrm{Cp}$-Ti and Ti6A14V substrate materials. The initial loading part was involved of an elastic-plastic displacement while the unloading section released the elastic energy. Table 3 presents the result of nanoindentation and elastic modulus measurements for coated and uncoated substrates of TiN/TiCN/TiC multilayer films. The mean values of hardness and elastic modulus of the films deposited on Cp-Ti substrates were 19.96 GPa and 162.81 GPa and on Ti6Al4V substrates were $19.96 \mathrm{GPa}$ and $162.81 \mathrm{GPa}$, respectively. These values are the average of 5 measurements taken on each sample. The highest hardness of the multilayer film,19.96 GPa, was obtained in coated Ti6Al4V substrate. Some authors have been reported hardness of TiN, TiCN and TiN/TiCN multilayer film with thickness of 0.5-6 $\mu \mathrm{m}$ which are about $8.2 \mathrm{GPa}$ to $27.3 \mathrm{GPa}$ [3, 25-27].

In multilayer films, existing of hard substratum layers strengthens the structure and wear resistance of the coating. This increment is due to an increase in the average hardness of the coating[28] . In the present study we found that the hard TiCN layer of film could raise general hardness and stability of the TiN/TiCN/TiC coatings. 
Multilayer films could improve mechanical properties of films like hardness in compared to every single-layered films. This improvement leads to high hardness and density and lower grain size, as observed in SEM images of Figure 4. It can be explained that high interface density of multilayered films leads to hinder dislocation movement and dislocation glide over the TiN, TiCN and $\mathrm{TiC}$ layers which could be justified by the differences in the elastic shear modulus of the individual layer materials [19].

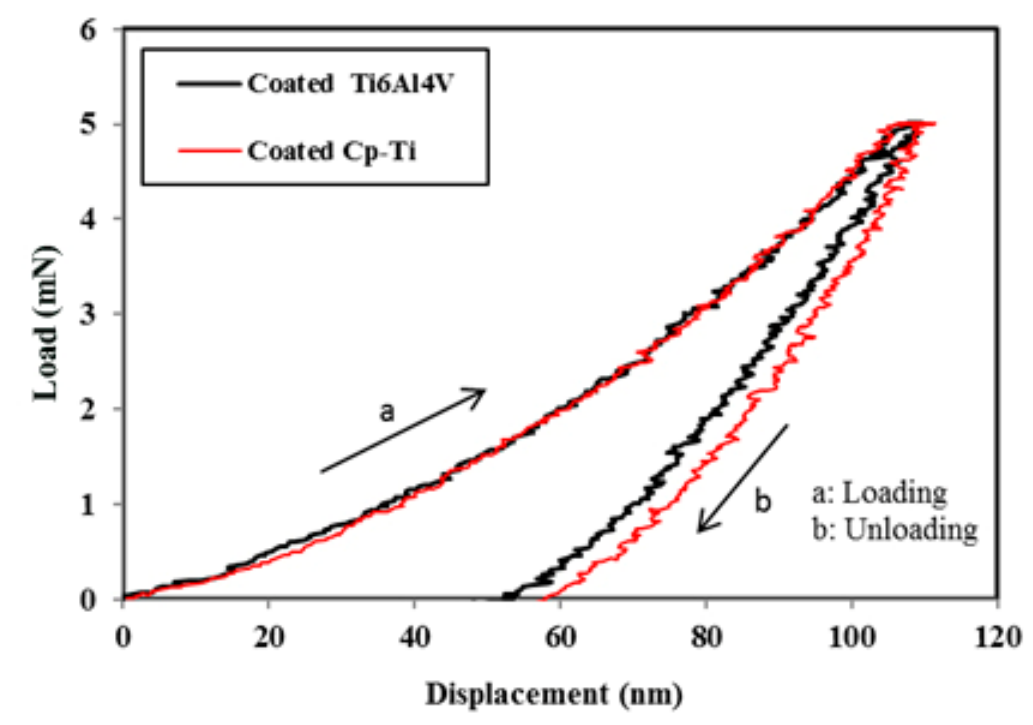

Figure 8. The typical loading-unloading curves of the TiN/TiCN/TiC multilayer film.

Table 3. Details of nanoindentation hardness measurements of TiN/TiCN/TiC coated and uncoated substrates

\begin{tabular}{lcc}
\hline Samples & Nanoindentation Hardness $(\mathrm{GPa})$ & Elastic modulus $(\mathrm{GPa})$ \\
\hline Coated Cp-Ti & 19.75 & 162.81 \\
Coated Ti6Al4V & 19.96 & 175.87 \\
Uncoated Cp-Ti & 3.15 & 93.71 \\
Uncoated Ti6Al4V & 4.81 & 99.37 \\
\hline
\end{tabular}

\section{CONCLUSIONS:}

The TiN/TiCN/TiC multilayered coatings were successfully deposited on silicon, CP-Ti and Ti6Al4V by CFUBMS method and thickness of film grown on silicon was $1.77 \mu \mathrm{m}$. According to the XRD and XPS spectrum of the TiN/TiCN/TiC coating, Ti, TiN, TiC and TiCN diffractions were detected in the coating. The most prominent crystallographic reflection in the coating was in the TiN (111) and TiCN (111) planes. The nano-hardness values of the coatings deposited on the surfaces of CP-Titanium and Ti6Al4V were measured as $19.75 \mathrm{GPa}$ and $19.96 \mathrm{GPa}$, respectively. Regarding to nano-hardness results, although hardness of substrates was increased by applying coating, there was no significant difference between the hardness values due to the proximity of 
substrate materials' harnesses to each other. In this study, the critical load values from the scratch test of TiN/TiCN/TiC were determined as $\mathrm{Lc}_{1}=6 \mathrm{~N}$ and $\mathrm{Lc}_{2}=14 \mathrm{~N}$ for the coated Cp-Titanium substrate material and $\mathrm{Lc}_{1}=10 \mathrm{~N}$ and $\mathrm{Lc}_{2}=17 \mathrm{~N}$ for the coated Ti6A14V surface. Scratch and nanoindentation tests showed that the coated Ti6Al4V substrate material with the $19.96 \mathrm{GPa}$ hardness value and $25 \mathrm{~N}$ critical load value presented the best mechanical behavior due to higher hardness and toughness of substrate in compared to $\mathrm{Cp}$-Ti substrate. With applying the coating of surface, the hardness of the coated materials was increased accompanied with achieving a high adhesion strength between the substrate and the coating

Acknowledgments: The Council of Higher Education (CoHE), Turkey (grant No. 2220830), Central Laboratory of Middle East Technical University (METU), Turkey, Research laboratory of Erzurum Technical University and East Anatolia High Technology Application and Research Center, Turkey, supported this research work.

Author Contributions: Ruhi Yeşildal conceived of the study, and participated in its design and coordination. Abbas Razmi analysed the data and participated in the discussions and helped to write and draft the manuscript. All authors read and approved the final manuscript

Conflicts of Interest: The authors declare that they have no competing interests.

\section{References}

1. Ataibis, V. and S. Taktak, Characteristics and growth kinetics of plasma paste borided CP-Ti and Ti6Al4V alloy. Surface and Coatings Technology, 2015. 279: p. 65-71.

2. Gao, C., et al., Advances in the induction of osteogenesis by zinc surface modification based on titanium alloy substrates for medical implants. Journal of Alloys and Compounds, 2017. 726: p. 1072-1084.

3. Bao, M., et al., Tribological behavior at elevated temperature of multilayer TiCN/TiC/TiN hard coatings produced by chemical vapor deposition. Thin Solid Films, 2011. 520(2): p. 833-836.

4. Wang, H.L., J.L. He, and M.H. Hon, Sliding wear resistance of TiCN coatings on tool steel made by plasma-enhanced chemical vapour deposition. Wear, 1993. 169(2): p. 195-200.

5. Saoula, N., et al., Influence of substrate bias on the structure and properties of TiCN films deposited by radio-frequency magnetron sputtering. Thin Solid Films, 2016. 616: p. 521-529.

6. $\mathrm{Mi}$, P., et al., Nanostructure reactive plasma sprayed TiCN coating. Surface and Coatings Technology, 2017. 309: p. 1-5.

7. Zhu, L., et al., Synthesis and microstructure observation of titanium carbonitride nanostructured coatings using reactive plasma spraying in atmosphere. Applied Surface Science, 2011. 257(20): p. 8722-8727.

8. Zambrano, G., et al., Hardness and morphological characterization of tungsten carbide thin films. Surface and Coatings Technology, 1998. 108-109: p. 323-327. 
9. Yao, S.H., et al., Wear behavior of DC unbalanced magnetron sputter deposited ZrCN films. Materials Letters, 2005. 59(26): p. 3230-3233.

10. Rie, K.T. and J. Wöhle, Plasma-CVD of TiCN and ZrCN films on light metals. Surface and Coatings Technology, 1999. 112(1): p. 226-229.

11. Devia, D.M., E. Restrepo-Parra, and P.J. Arango, Comparative study of titanium carbide and nitride coatings grown by cathodic vacuum arc technique. Applied Surface Science, 2011. 258(3): p. 1164-1174.

12. Zheng, J., et al., $A$ thick TiN/TiCN multilayer film by DC magnetron sputtering. Surface and Coatings Technology, 2012. 209: p. 110-116.

13. Wang, S.-S., et al., Effect of NbN and ZrN films formed by magnetron sputtering on Ti and porcelain bonding. Surface and Coatings Technology, 2010. 205(7): p. 1886-1891.

14. Latella, B.A., et al., Titanium nitride/vanadium nitride alloy coatings: mechanical properties and adhesion characteristics. Surface and Coatings Technology, 2006. 200(11): p. 3605-3611.

15. Antunes, R.A., et al., Study of the corrosion resistance and in vitro biocompatibility of PVD TiCNcoated AISI $316 \mathrm{~L}$ austenitic stainless steel for orthopedic applications. Surface and Coatings Technology, 2010. 205(7): p. 2074-2081.

16. Su, Y.L. and W.H. Kao, Tribological Behavior and Wear Mechanisms of TiN/TiCN/TiN Multilayer Coatings. Journal of Materials Engineering and Performance, 1998. 7(5): p. 601-612.

17. Behrens, B.A. and A. Huskic, Wear reduction on dies for precision forging of gear wheels by means of multi-layer coating (TiN-TiCN-TiC). Materialwissenschaft und Werkstofftechnik, 2005. 36(5): p. 218-225.

18. Li, J., et al., Tribological properties in seawater for Ti/TiCN coatings on Ti6Al4V alloy by arc ion plating with different carbon contents. Vol. 36. 2016.

19. Caicedo, J.C., et al., TiCN/TiNbCN multilayer coatings with enhanced mechanical properties. Applied Surface Science, 2010. 256(20): p. 5898-5904.

20. Cheng, Y. and Y.F. Zheng, Characterization of TiN, TiC and TiCN coatings on Ti-50.6 at.\% Ni alloy deposited by PIII and deposition technique. Surface and Coatings Technology, 2007. 201(9): p. 4909-4912.

21. Tillmann, W. and S. Momeni, Tribological development of TiCN coatings by adjusting the flowing rate of reactive gases. Vol. 90. 2015.

22. Bhushan, B., Introduction to Tribology, 2nd edition. 2013: Wiley.

23. Bull, S.J., Failure mode maps in the thin film scratch adhesion test. Tribology International, 1997. 30(7): p. 491-498.

24. Perry, A.J., Scratch adhesion testing of hard coatings. Thin Solid Films, 1983. 107(2): p. 167-180.

25. Peters, A.M. and M. Nastasi, Effect of carrier gas on the deposition of titanium carbo-nitride coatings by a novel organo-metallic plasma immersion ion processing technique. Vacuum, 2002. 67(2): p. 169-175.

26. Bemporad, E., et al., Characterization and hardness modelling of alternate TIN/TICN multilayer cathodic arc PVD coating on tool steel. Surface and Coatings Technology, 2001. 146-147: p. 363370.

27. Kim, G.-H., A.G. Rand, and S.V. Letcher, Impedance characterization of a piezoelectric immunosensor: Part I: Antibody coating and buffer solution. Biosensors and Bioelectronics, 2003. 18(1): p. 83-89.

28. Anand, M., et al., Tribological evaluation of soft metallic multilayer coatings for wear applications based on a multiple pass scratch test method. Wear, 2017. 388-389: p. 39-46. 